\title{
The Precipitation Depth Distribution of Small Catchment - A case in South of Taiwan
}

\author{
Chi Tang ${ }^{1, a}$, Ya-Lin Huang ${ }^{1, b}$, Yao-Ming Hong ${ }^{2, c}$ \\ ${ }^{1}$ Department of Soil and Water Conservation, National Pingtung University of Science and \\ Technology, Pingtung 91201, Taiwan \\ ${ }^{2}$ Department of Design for Sustainable Environment, MingDao University, No. 369 Wen-Hua Road, \\ Peetow, Changhua 52345, Taiwan \\ a tangchi@mail.npust.edu.tw, b rebecca_lyle@hotmail.com, cblueway@mdu.edu.tw
}

Keywords: Kriging method, small catchment, rainfall depth.

\begin{abstract}
This study established the estimation method of rainfall distribution for small catchment. The Kriging method was introduced to establish the spatial distribution model of rainfall depth, where the cross validation is executed to verify the theoretical semi-variogram model. A field experiment with an area of 3.33ha was executed for nearly three years in southern Taiwan, and obtained the rainfall depth data from 167 rainfall events of 12 rainfall stations. After the statistical analysis, we found that the Gaussian model is suitable to establish the theoretical semi-variogram of rainfall depth, so as to estimate the rainfall depth of ungauged region.
\end{abstract}

\section{Introduction}

Hillslope occupies 70\% area in Taiwan. In summer times, Typhoon usually induces a serious disaster such as flood or debris flow [1]. Moreover, a long time drought in winter of south Taiwan frequently brings the lack of water. Therefore, the precise rainfall prediction is important for the disaster warning and the water resources management in the south of Taiwan. In addition, the micrometeorological determination is helpful for the management of farm or orchard [2]. More rainfall stations can increase the estimation precision of precipitation. However, the rainfall stations have a limited number due to the budget. Therefore, the location determination of rainfall station is an important issue in Taiwan.

In recent years, due to the development of geographic information system (GIS) and the global scale hydrology, the research on the spatial distribution of precipitation (SDP) is more important than before. Kriging method, which is developed from the regionalized variable theory, adopts the precipitation as the spatial variable, and has the best linear unbiased estimator (BLUE) [3]. Generally speaking, Kriging method can get better rainfall estimation than the linear regression methods such as Thiessen's Polygon Method or Reciprocal square distance interpolation. For examples, the Kriging method can be used to calculate the precipitation depth of ungauged sites and estimate the network of rain stations [4]. The maximum Kriging variance can be used to redesign the location of rainfall stations, so as to reach the optimum design for the network of rainfall stations [5]. This study analyzes the changes of time and space for the precipitation distribution of small catchment using the Kriging method. 12 rainfall stations were set up in the watershed of the Thorny Bamboo Plantation, located in the National Pingtung University of Science and Technology, so as to form a monitoring network of rainfall depth. The validation of theoretical semi-variogram model was analyzed.

\section{The Description of Statistical Method}

\section{The Kriging Method}

The Kriging method is based on the hypothesis of second-order stationary. Assuming the expected value $\mathrm{E}[Z(x)]$ of regionalized variable $\mathrm{Z}(\mathrm{x})$ is a constant $\mathrm{m}$, which will not be changed by the position. 


$$
\mathrm{E}[Z(x)]=m
$$

The covariance $C$ of $\mathrm{Z}(x)$ is dependent on the relative distance between $\mathrm{x}_{1}$ and $\mathrm{x}_{2}$, and independent on the position.

$\mathrm{E}\left\{\left[Z\left(x_{1}\right)-m\right]\left[Z\left(x_{2}\right)-m\right]\right\}=C\left(x_{1}, x_{2}\right)$

If $x_{1}=x_{2}$, then

$$
C(0)=E\left\{\left[Z\left(x_{1}\right)-m\right]^{-2}\right\}=\sigma^{2}=\text { const }
$$

where $\sigma^{2}$ is the variogram. However, the hypothesis of second-order stationary is an ideal condition and cannot fix the general condition. Therefore, the intrinsic hypothesis is proposed. Defining $h_{i}=\left|x_{1}-x_{2}\right|$, Then

$$
\begin{aligned}
& \mathrm{E}\left[Z\left(x_{1}\right)-Z\left(x_{2}\right)\right]=m\left(h_{i}\right) \\
& \operatorname{Var}\left[Z\left(x_{1}\right)-Z\left(x_{2}\right)\right]=2 \gamma\left(h_{i}\right)
\end{aligned}
$$

where $\operatorname{Var}[]$ is the variance, $\gamma\left(h_{i}\right)$ is the semi-variance. If $\mathrm{m}\left(h_{i}\right)=0$ and $\operatorname{Var}[Z(x)]=$ const, the relationship between $\gamma\left(h_{i}\right)$ and covariance $\mathrm{C}\left(h_{i}\right)$ will be

$$
\gamma\left(h_{i}\right)=\mathrm{C}(0)-\mathrm{C}\left(h_{i}\right)
$$

In the Kriging method, the $Z(0)$ of known position is used to estimate the $Z^{*}(0)$ in unknown position. There are several characteristics as follows.

(a) Linear: Estimate is the linear combination of observations.

$$
Z_{0}^{*}=\sum_{i=0}^{N} \lambda_{0}^{i} Z_{i}
$$

where $\lambda_{0}^{i}$ is a constant.

(b) Unbiased: The expected value of estimate equals to the expected value of random value.

$$
\mathrm{E}\left[Z_{0}^{*}-Z_{0}\right]=0
$$

(c) Optimal: The variance between the estimate and observation is minimal.

$$
\operatorname{Var}\left[\mathrm{Z}_{0}^{*}-\mathrm{Z}_{0}\right]=\min
$$

where min is the abbreviation of minimum.

\section{The Indexes of Test Model}

The cross validation is a technique for estimating the performance of a predictive model. In this study, it is used to verify the merit points of theoretical variance, and the hypothesis reasonableness of Kriging method. Selecting one rainfall station as the reference station, the other rainfall stations are used to calculate the spatial distribution of rainfall depth, which will be adopted to estimate the rainfall depth for the reference station. The following equations can be used to verify the correctness between observed/estimated rainfall depth of the reference station.

(a) Standardized Kriging average error (SKAE)

A small SKAE (close to zero) represents a good unbiased value of theoretical variance

$$
S K A E=\frac{1}{n} \sum_{i=0}^{n}\left[\frac{\left(Z_{i}^{*}-Z_{i}\right)}{\sigma_{Z_{i}}}\right]
$$

where $n$ is the sample size, $Z_{i}$ and $Z_{i}^{*}$ are the estimated and observed data at the $i$ point. $\sigma_{z_{i}}$ is the standard deviation at the $i$ point.

(b) Standardized Kriging variance (SKV)

The consistency exists between estimated/observed data if SKV is close to 1.

$$
S K V=\frac{1}{n} \sum_{i=0}^{n}\left[\frac{\left(Z_{i}^{*}-Z_{i}\right)^{2}}{\sigma_{Z_{i}}^{2}}\right]^{\frac{1}{2}}
$$

where $\sigma_{Z_{i}}^{2}$ is the Kriging variance.

(c) Mean absolute error (MAE) 
MAE can estimate the overall merit points for various interpolation method.

$M A E=\sum_{i=0}^{n}\left[Z_{i}^{*}-Z_{i}\right]$

\section{Description of Field Area}

The experiment watershed (Fig. 1), geographic coordinates of $22^{\circ} 38^{\prime} 20.6^{\prime} \mathrm{N}$ latitude and $120^{\circ} 36^{\prime} 48.4^{\prime \prime} \mathrm{E}$ longitude, is located in the soil and water conservation outdoor classroom of National Pingtung University of Science and Technology. The watershed area is 3.33ha, with 310m long and 65 to $110 \mathrm{~m}$ wide, elevation range between $90-50 \mathrm{~m}$, and average slope $7.4^{\circ}$. A valley passes through the watershed from north northwest to south-southeast, where the slope of the right hand hillside is $21.8^{\circ}$, and left hand $18.3^{\circ}$, respectively. The main species of the watershed are thorny bamboo, which occupies $65 \%$ area with average canopy height $=16.9 \mathrm{~m}$ (Tang et al. 2009). Generally speaking, the air flow path will be controlled by the valley topography, so as to influence the spatial distribution of inner rainfall. The flat regions in the ridge/valley line of watershed were selected as the position of rainfall stations. Figure 1 is the experimental region and the position of 12 rainfall stations.

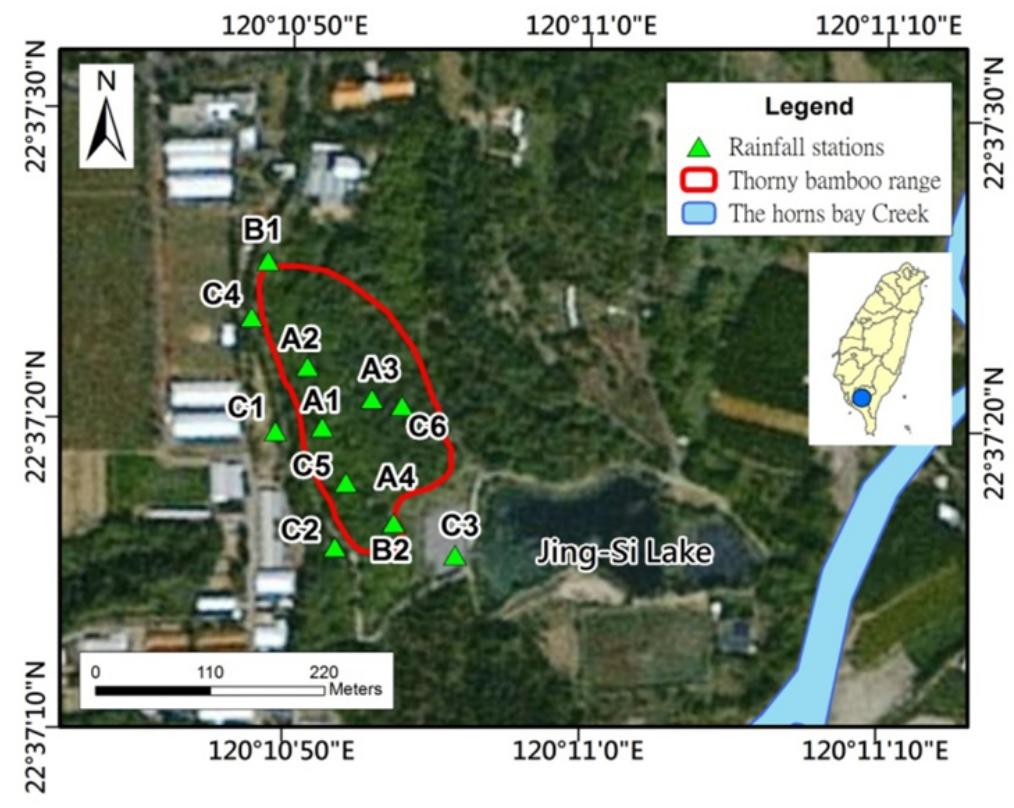

Figure 1. The experimental region and the position of 12 rainfall stations

\section{The Kriging method}

Generally speaking, the commonly used theoretical semi-variogram models include Linear, Power, Gaussian, and Spherical model [6]. The cross validation method is used to obtain the SKAE and SKV by Equation (10) and (11). For the comparison of the consistence and the unbiasedness between four models, this study assumed a priority factor $\mathrm{P}=\mathrm{SKAE}^{2}+(\mathrm{SKV}-1)^{2}$. The model with minimum $P$ represents the best method for the period, and the priority value $=1$. Summing the priority value of four periods, the model with minimum sum value is the best model for the study area entirely. Table 1 displays the calculation outcomes, where the Gaussian model is a better model than others.

Table 1 The selection of theoretical semi-variogram model

\begin{tabular}{|c|c|c|c|c|c|}
\hline Period & Model & SKAE & SKV & P & Priority \\
\hline \multirow{4}{*}{ Year } & Linear & 0.052 & 0.606 & 0.158 & 2 \\
\cline { 2 - 6 } & Power & 0.002 & 8.413 & 54.95 & 4 \\
\cline { 2 - 6 } & Gaussian & 0.002 & 1.591 & 0.349 & 3 \\
\cline { 2 - 6 } & Spherical & 0.044 & 1.264 & 0.072 & 1 \\
\hline
\end{tabular}




\begin{tabular}{|c|c|c|c|c|c|}
\hline \multirow{3}{*}{ month } & Linear & 0.287 & 0.044 & 0.996 & 1 \\
\cline { 2 - 6 } & Power & 0.252 & 0.044 & 0.977 & 2 \\
\cline { 2 - 6 } & Gaussian & 0.014 & 0.002 & 0.996 & 4 \\
\cline { 2 - 6 } & Spherical & 0.014 & 0.009 & 0.982 & 3 \\
\hline \multirow{3}{*}{ wet } & Linear & 0.047 & 1.073 & 0.008 & 2 \\
\cline { 2 - 6 } & Power & 0.014 & 0.878 & 0.015 & 4 \\
\cline { 2 - 6 } & Gaussian & 0.041 & 1.05 & 0.004 & 3 \\
\cline { 2 - 6 } dry & Spherical & 0.047 & 1.049 & 0.005 & 1 \\
\hline & Linear & 1.521 & 2.599 & 4.870 & 4 \\
\cline { 2 - 6 } & Power & 0.577 & 0.244 & 0.904 & 1 \\
\cline { 2 - 6 } & Gaussian & 0.575 & 0.243 & 0.904 & 2 \\
\cline { 2 - 6 } & Spherical & 0.575 & 0.243 & 0.904 & 2 \\
\hline
\end{tabular}

\section{Conclusion}

This study established the estimation method of rainfall distribution for small catchment. The statistical method named Kriging method was introduced to establish the spatial distribution of rainfall depth. The cross validation was also used to test the validation of theoretical semi-variogram model. A field experiment with an area of 3.33ha was executed for nearly three years in south Taiwan. According the data obtained from 167 rainfall events of 12 rainfall stations, and the analysis of cross validation, the Gaussian model is the best model of theoretical semi-variogram than others in the study area. In the future, we can use the Gaussian model to establish the theoretical semi-variogram of rainfall depth, so as to estimate the rainfall depth of ungauged region.

\section{Reference}

[1] Hong Y.M., Wan S., in: An Information-Based System Identification for Measurements on Groundwater Level Fluctuation of Hillslope, Hydrogeology Journal, Vol.19(2011), p.1135-1149.

[2] Tang C., Yu F.C., Hsu S.H. , in: Characteristics of the thermal environment of a natural Machilus zihoensis woods., Chinese J. Soil Water Conserv. , Vol.34 (2003), p.113-127. (in Chinese with English abstract)

[3] Goovaerts, P., in: Geostatistical Approaches for Incorporating Elevation into the Spatial Interpolation of Rainfall., Journal of Hydrology, Vol.228 (2000), p.113-129.

[4] Hughes, T., W. Liu and T. Zimmermann., in: Lagrangian-eulerian finite-element formulation for incompressible viscous flows. Comput. Methods Appl. Mech. Engrg., Vol.29,3 (1981), p.329-349.

[5] Virdee, T.S. and Kottegoda N.T., in: A Brief Review of Kriging and its Application to Optimal Interpolation and Observation Well Selection., Hydrological Sciences Journal, Vol.29,4 (1984), p.367-387.

[6] Davis, J. C.: Statistics and data analysis in geology, John Wiley \& Sons, New York, (1973). 